\title{
Blood components are essential to regulate microcirculatory blood flow
}

\author{
Nicolas Morel $^{1 *}$ and Marie Moisan ${ }^{2}$ \\ See related review article by Jacob et al., http://ccforum.biomedcentral.com/articles/10.1186/s13054-016-1485-0
}

We read with interest the article by Jacob and colleagues [1] on the regulation of microcirculatory blood flow. In our opinion, the authors missed an important parameter, i.e., blood components and, particularly, red blood cells (RBC). This is regrettable since blood composition is the main parameter that we can influence by our therapies (fluid resuscitation, blood or albumin transfusion) in shocked patients.

RBC may use different contradictory pathways to modulate microvascular flow by modifying nitric oxide (NO) bioavailability, which is responsible for precapillary dilatation and capillary perfusion.

On the one hand, erythrocytes may reduce NO bioavailability through hemoglobin NO scavenging; on the other hand, enhancing hematocrit may increase viscosity and wall shear stress (WSS), a crucial agonist enabling endothelium NO release.

Thus, in hypoxic conditions, $\mathrm{RBC}$ may sense tissue oxygen tension and release vasodilatory agents such as NO or ATP.

In moderate hemodilution, blood viscosity is reduced, cardiac output increases, wall shear rate (WSR; blood velocity) increases and WSS is unchanged (WSS $=$ WSR $\times$ viscosity). NO bioavailability increases because of reduced NO scavenging by erythrocytes, leading to systemic vasoplegia. In extreme hemodilution [2] (hematocrit at $11 \%)$, viscosity, WSR, and WSS drop. Functional capillary density (FCD), which reflects microcirculatory flow, decreases. In this model, enhancing blood viscosity with high viscosity-plasma expander increased FCD. In the same way, in a murine model of hemorrhagic shock, transfusion of fresh $\mathrm{RBC}$ without oxygen-carrying capacity restored blood viscosity, and enhanced FCD, microvascular flow, and systemic hemodynamics. Recently, Tanaka and colleagues [3] observed that RBC transfusion improved sublingual FCD in humans in hemorrhagic shock with active blood loss.

We have known since 1999 from the results of a trial using modified human hemoglobin in traumatic hemorrhagic shock [4] that modifying blood properties could be harmful. Patients in this study had a better blood systolic pressure than control patients, but more of them died. Free hemoglobin scavenges NO, enhancing precapillary vasoconstriction and impairing capillary perfusion.

We do not share the authors' opinion that it is "better to choose hemorrhagic rather than septic shock for yourself". Guidelines for traumatic hemorrhagic shock management [5] do not consider RBC transfusion for their microcirculatory properties and viscosity improvement, but only for their oxygen-delivering capacity, which is altered for many hours after transfusion, when blood is stored. Recommending a low hemoglobin trigger delays RBC transfusion when microcirculation flow is already impaired.

\section{Authors' response}

\section{Matthias Jacob, Daniel Chappell and Bernhard F. Becker}

Nicolas Morel and Marie Moisan have drawn attention to the special but confounding role played by $\mathrm{RBC}$ in modulating regional microcirculatory flow distribution. As they correctly point out, contributory effects include changes in blood viscosity and scavenging or provision

\footnotetext{
* Correspondence: nicomorel2@gmail.com

${ }^{1}$ Service de réanimation polyvalente, Polyclinique Jean Villar, Avenue Maryse Bastié, 33520 Bruges, France

Full list of author information is available at the end of the article
}

of vasoactive metabolites. Such influences must be expected, especially in conjunction with transfusions of $\mathrm{RBC}$ in situations of treatment or prevention of shock [6]. Although the effect of blood transfusion on blood viscosity and flow resistance has fascinated physiologists and experimental clinicians for over 100 years, the action of RBC on blood flow distribution has not been resolved satisfactorily. This is, in part, due to the fact that microvascular flow resistance arises mainly from 
the leukocyte component of whole blood, and not from RBC-mediated changes in viscosity [7]. With respect to scavenging of endothelium-derived vasodilatory $\mathrm{NO}$ by the hemoglobin of RBC, such an effect may be countered by the recently described presence of an active type-3 NO synthase in RBC [8]. In addition, supplying oxygen to the tissue provokes the production of vasoconstrictors in vivo. This realization has disproved other hypotheses proposing oxygen-dependent destruction or removal of vasodilators by RBC [9].

These few examples of the problems still associated with understanding the mechanisms by which RBC may influence regional flow distribution illustrate the continued necessity of conducting well-planned clinical studies for the improvement of patient outcome in situations of shock. Although at first sight the approach to management of traumatic hemorrhagic shock seems more clear than that of septic states, Morel and Moisan have provided good reasons why this is not resolved.

\section{Acknowledgements}

None.

\section{Funding}

Not applicable.

\section{Availability of data and materials}

Not applicable.

\section{Authors' contributions}

NM and MM were involved in writing and drafting the manuscript as well as revising it critically for important intellectual content. Both authors read and approved the final manuscript.

\section{Competing interests}

The authors declare that they have no competing interests.

\section{Consent for publication}

Not applicable.

Ethics approval and consent to participate

Not applicable.

\section{Author details}

'Service de réanimation polyvalente, Polyclinique Jean Villar, Avenue Maryse Bastié, 33520 Bruges, France. ${ }^{2}$ Pôle des urgences adultes, Hôpital Pellegrin CHU Bordeaux, Place Amélie Raba Léon, 33000 Bordeaux, France.

Received: 10 December 2016 Accepted: 30 January 2017

Published online: 08 March 2017

\section{References}

1. Jacob M, Chappell D, Becker BF. Regulation of blood flow and volume exchange across the microcirculation. Crit Care. 2016;20(1):319.

2. Tsai AG, Acero C, Nance PR, Cabrales P, Frangos JA, Buerk DG, Intaglietta M. Elevated plasma viscosity in extreme hemodilution increases perivascular nitric oxide concentration and microvascular perfusion. Am J Physiol Heart Circ Physiol. 2005;288(4):H1730-9.

3. Tanaka S, Escudier E, Hamada S, Harrois A, Leblanc PE, Vicaut E, Duranteau J. Effect of RBC transfusion on sublingual microcirculation in hemorrhagic shock patients: a pilot study. Crit Care Med. 2017;45(2):e154-e160.

4. Sloan EP, Koenigsberg M, Gens D, Cipolle M, Runge J, Mallory MN, Rodman Jr G. Diaspirin cross-linked hemoglobin (DCLHb) in the treatment of severe traumatic hemorrhagic shock: a randomized controlled efficacy trial. JAMA. 1999;282(19):1857-64.
5. Rossaint R, Bouillon B, Cerny V, Coats TJ, Duranteau J, Fernandez-Mondejar E, Filipescu D, Hunt BJ, Komadina R, Nardi G, et al. The European guideline on management of major bleeding and coagulopathy following trauma: fourth edition. Crit Care. 2016:20:100.

6. Weinberg JA, Patel RP. Red blood cell transfusion and its effect on microvascular dysfunction in shock states. Best Pract Res Clin Anaesthesiol. 2016;30(4):491-8.

7. Donati A, Damiani E, Luchetti M, Domizi R, Scorcella C, Carsetti A, Gabanelli V, Carletti P, Bencivenga R, Vink H, Adrario E, Piagnerelli M, Gabrielli A, Pelaia $P$, Ince $C$. Microcirculatory effects of the transfusion of leukodepleted or non-leukodepleted red blood cells in patients with sepsis: a pilot study. Crit Care. 2014;18(1):R33.

8. Cortese-Krott MM, Kelm M. Endothelial nitric oxide synthase in red blood cells: key to a new erythrocrine function? Redox Biol. 2014;2:251-8.

9. Jackson WE. Arteriolar oxygen reactivity: where is the sensor and what is the mechanism of action? J Physiol. 2016:594(18):5055-77. 